\title{
DIRECTIONAL PREFERENCES OF THE ROBIN (Erithacus rubecula) AND THE BLACKCAP (Sylvia atricapilla) DURING AUTUMN MIGRATION AT AROSIO (N ITALY) IN 2005
}

\author{
Karolina Adamska and Katarzyna Rosińska
}

\begin{abstract}
Adamska K., Rosińska K. 2006. Directional preferences of the Robin (Erithacus rubecula) and the Blackcap (Sylvia atricapilla) during autumn migration at Arosio (N Italy) in 2005. Ring 28, 2: 101-111.

Results of orientation tests of nocturnal migrants with the use of Busse's cage (Busse 1995, Busse 2000) are described in this paper. That method enables to study directional behaviour of nocturnal migrants during daytime. The aim of these studies is the description of directional preferences of the Robin and the Blackcap at the ringing station Arosio, northern Italy. Totally, 220 orientation tests for the Robin and 77 for the Blackcap were performed. Tested species have shown differentiation of directional preferences. Distribution of directions for the Robin is very clear. One direction was preferred - SSE direction (34\%). For the Blackcap the distribution of headings was more complex, but two main directions could be distinguished - SSW (23\%) and WSW (22\%). Migration patterns of both these species in Europe are complicated. Birds migrating through northern Italy should be regarded as different migrating populations (Remisiewicz 2002, Mokwa 2004). However, migration pattern of the Robin was strongly determinated in one SSE direction, which indicates the Apennine Peninsula. Blackcap followed two directions, which indicate western winter quarters. Obtained results stood in accordance with other data, such as recoveries. Although the obtained results seem to be very interesting and promising, only intensive studies, especially in areas indicated by tested birds, could give information about migration pattern of these species.
\end{abstract}

K. Adamska, K. Rosińska, Bird Migration Research Station, University of Gdańsk, Przebendowo, PL-84-210 Choczewo, Poland, E-mail: bioka@univ.gda.pl, biokr@univ.gda.pl; NIBBIOFEIN Foundation, Arosio Bird Observatory, Via Cascina Perego, 1, 22060 Arosio (CO), Italy. Publication appointed to the SE European Bird Migration Network papers

Key words: Robin, Blackcap, orientation tests, Northern Italy

\section{INTRODUCTION}

In order to conduct comprehensive studies on migration we have to include migration strategy, population differentiation, migration directions, bird physiological 
condition into our analyses (Busse 1992). The most popular method to deepen our knowledge about birds' migration is still catching and ringing birds. Data received from analysing ringing recoveries is valuable method to get acquainted with migration strategies and migratory routes of birds. Studying directionality of nocturnal migrants is much more complicated than that of daytime migrants, because they move in darkness. Studies on this topic include highly specialized research methods. One of the most popular methods are orientation tests. We make use of the fact that during migration birds behave directionally flying from breeding grounds towards winter quarters. Direction of bird migration is genetically fixed and modified by physiological and environmental factors (Gwinner and Wiltschko 1978, Akesson 1993). First experiments with the use of orientation cage were conducted by Kramer (1949) and Sauer (1957). Such experiments were usually used to study mechanism of orientation and not directional behaviour of birds at different localities on the migration route. Kramer's and Sauer's cages were round structures with a system of electrical devices registering behaviour of caged birds. These methods were difficult to adapt in fieldwork, besides, birds were caged a long time after catching. A simpler experimental cage was designed by Emlen and Emlen (1966) - birds were tested in a round cage, where a bird jumped on a slope wall and fell down after every jump. This method was criticised because it made birds stressed, which could have had influence on birds' behaviour in the cage. Besides, experiments were performed at night, and as in the previously mentioned case, a long time after catching. The new type of experimental cage was designed by Busse (1995). Author stated that cage experiments could be a useful method if the stress of birds was reduced as much as possible. This method enables to study directional behaviour of nocturnal migrants during daytime in the field conditions.

Many Western Palearctic passerine birds cross the Alps to move to their winter quarters through the Italian Peninsula on their post-breeding migration (Schubert et al. 1986). Therefore, cage experiments were important for the evaluation of models of migration strategies. In this paper we present the results of studies on typical night migrants: the Robin and the Blackcap. Autumn migration of the Robin lasts from September till the end of October. Northern and central European populations migrate to wintering grounds in western and southern Europe, northern Africa and Asia Minor. Northern and eastern populations of the Blackcap are wholly migratory, southern ones - partially migratory. Northern populations cover the longest distance, reaching south of winter range, and populations further south apparently move progressively less far (Cramp 1993). The aim of these studies was to examine directional preferences of the Robin and Blackcap during autumn migration at the Arosio Bird Observatory in northern Italy (Pre-Alps).

\section{MATERIAL AND METHODS}

Data were collected in 2005 during autumn migration at the Arosio Bird Observatory, Lombardy region in northern Italy $\left(45^{\circ} 43^{\prime} \mathrm{N}, 9^{\circ} 12^{\prime} \mathrm{E}\right)$. It is placed $360 \mathrm{~m}$ a.s.l., 
on the top of hill facing the Po valley (western part of the Pre-Alps). Arosio lies on one of the main migratory flyways for passerines, representing an important stopping and feeding area and is set in a large forest dating back to 1710 . The data were collected for 30 days - from 28 September till 28 October in 2005. The most intensive period of migration of the Robin and Blackcap was comprised in this term (Schubert et al. 1986, Scebba and Capasso 2006).

Tape luring and mist-nets were used to catch the birds. Birds were ringed and measured and then as soon as is it was possible, tested for directional behaviour in orientation cages. All tests were performed with the use of Busse's cage, according to the standard method proposed by this researcher (Busse 1995, Busse 2000). The cage was a flat circular structure with a wall divided into eight sectors; it was placed in protecting screen according to N-S axis. Preparation of the cage for the experiment included covering its vertical side wall with a stripe of a foil from a roll with the use of transparent sticky tape. Scratches and holes on a foil were treated as signs of bird activity and counted sector by sector. Cage experiments were performed at the roof of the observatory building, which was placed on the hill. Most experiments were conducted during the daytime: 6.00 a.m. -7.00 p.m., only 29 Robins were tested after sunset, all birds were tested not later than two hours after they had been caught in the nets.

The raw data set was computerised using program ORIENT 4.5 (P. Busse, University of Gdańsk). Data were elaborated using non-standard method for evaluation of circular data proposed by Busse and Trocińska (1999) and also described by Busse et al. (2001), Trocińska et al. (2001) to show multimodal distribution. A standard procedure used previously (e.g. Helbig et al. 1989, Helbig 1991, Berthold et al. 1992) and applied to the individual orientation data assumed unimodal bird behaviour, thus individual bird heading was an average of raw data defined by a direction given in degrees $(\alpha)$ and the length of a vector $r$. When data for group of birds were considered - all individual vectors were summed and given as a group vector. Migration direction was given as an angle (azimuth) and the vector length illustrating data dispersion. In the calculation procedure applied in the present study welldocumented multimodal distributions were used (Busse and Trocińska 1999, Busse et al. 2001, Trocińska et al. 2001). Obtained results were given as the simplified 16sectors radar graphs based on a wind-rose. The polygons reflecting relative number of tested birds were used to get a clear picture. These radar graphs were modified (cut and flattened) and presented as linear graphs. This technique allowed to select average azimuths of preferred directions.

The results have been compared with other data like recoveries. Material has been collected since 1975 (Vigorita and Reguzzoni 2004) at the Arosio Bird Observatory and other ringing stations (40 sites) in Lombardy region. Angles and distances were elaborated using RECRING 2.3 software by P. Busse. 


\section{RESULTS}

Totally, 304 orientation tests were performed. Only seven tested individuals $(1.7 \%)$ - five Robins and two Blackcaps - were categorized as "not active", i.e. the total number of scratches in one test was less than 20, and were excluded from further analyses. 297 individuals showed clear preferences (data distributions differed significantly from random $-\chi^{2}$-test: $p<0.01$ ), finally, 220 orientation tests for the Robin and 77 for the Blackcap were elaborated.

Tested species have shown differentiation of directional preferences. Total distributions of the preferred directions of tested species are given in Figure 1. Distribution of directions for the Robin is very clear. One direction was strongly dominant - SSE direction (34\%), the average azimuth was $163^{\circ}$. Not clearly marked on radar graphs SW direction was dispersed and its percentage was $23 \%$ and average azimuth $-248^{\circ}$ (specified using linear graph - Figure 2). For the Blackcap distribution of headings was more complicated, but two main directions could be distinguished - SSW direction was dominant (23\%), but WSW direction was also significant $(22 \%)$. The average azimuths were: $197^{\circ}$ (SSW) and $240^{\circ}$ (WSW). Percentage of the northern (reversed) directions, opposite to normal direction during autumn migration observed in Arosio was not so high and it was the same for two tested species $-37 \%$, and in both cases $-19 \% \mathrm{NW}$ and $18 \%$ NE. A share of reversed headings on NW-SE axis was higher $-40 \%$ for the Robin and $45 \%$ for the Blackcap, while on NE-SW axis was respectively $-35 \%$ and $31 \%$.
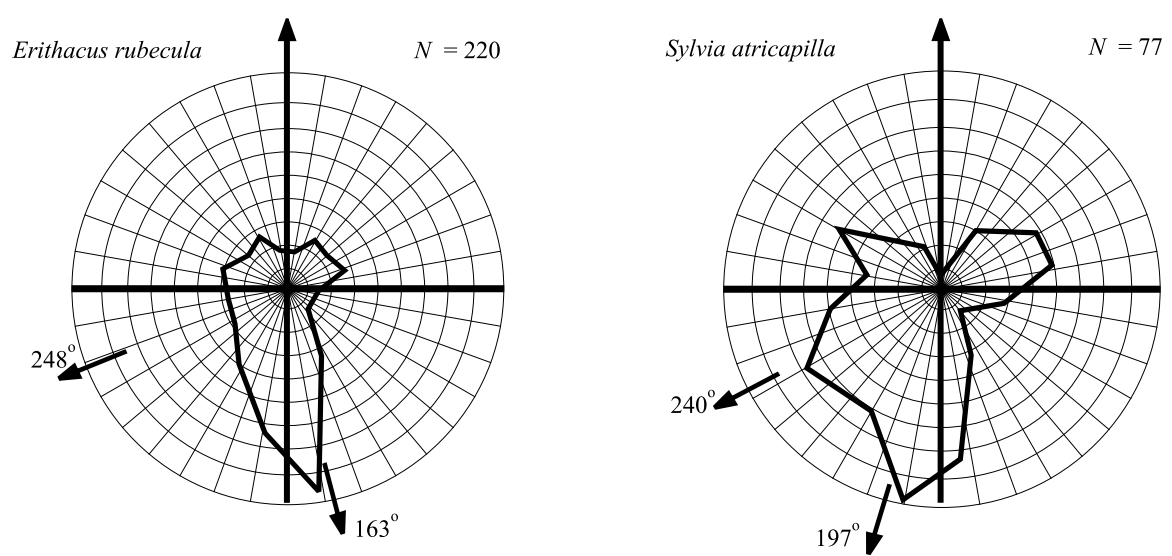

Fig. 1. Distributions of the preferred directions (given in 16 sectors) shown by the Robin (left panel) and the Blackcap (right panel) in 2005. Arrows - average azimuths

Altogether 25 ringing recoveries of Robins ringed at Arosio were obtained. 17 of them were ringed during autumn migration and found at winter quarters. Among 

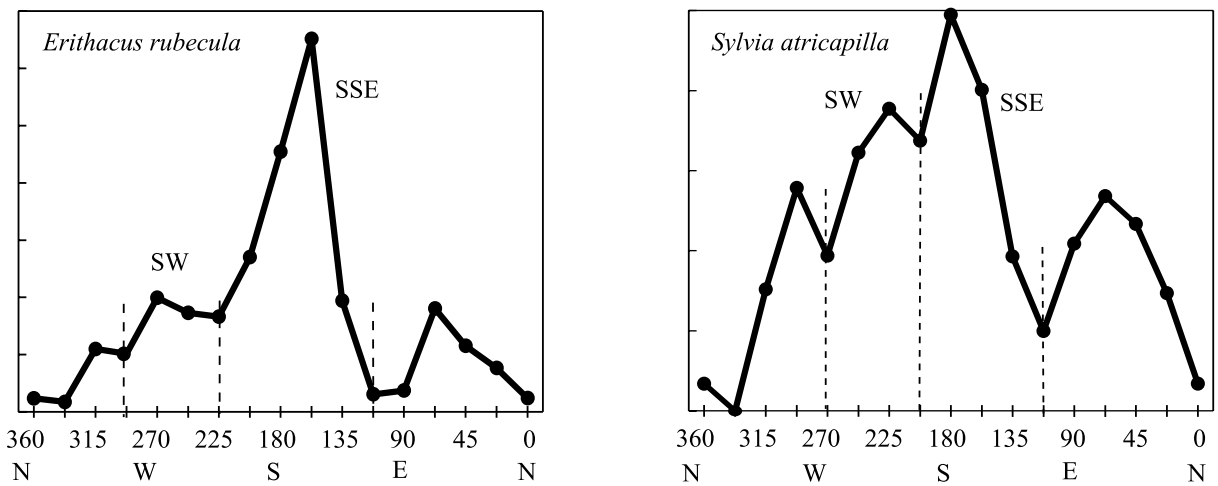

Fig. 2. Distributions of the preferred directions (given in linear graphs) shown by the Robin (left panel) and the Blackcap (right panel) in 2005

them, $16(76 \%)$ individuals were recorded in Algeria along the Mediterranean Sea coastline (distance - above $1100 \mathrm{~km}$, average angle $-203^{\circ}$ ), most of them were ringed in October and found in Algeria in December or January. One bird ringed in October was recorded in Morocco (45 days after ringing, $1666 \mathrm{~km}, 229^{\circ}$ ). Distribution of recoveries for the whole Lombardy region is quite similar (Fig. 3). Concentrations of recoveries were noted in Algeria: about 71 records of Robins, one of

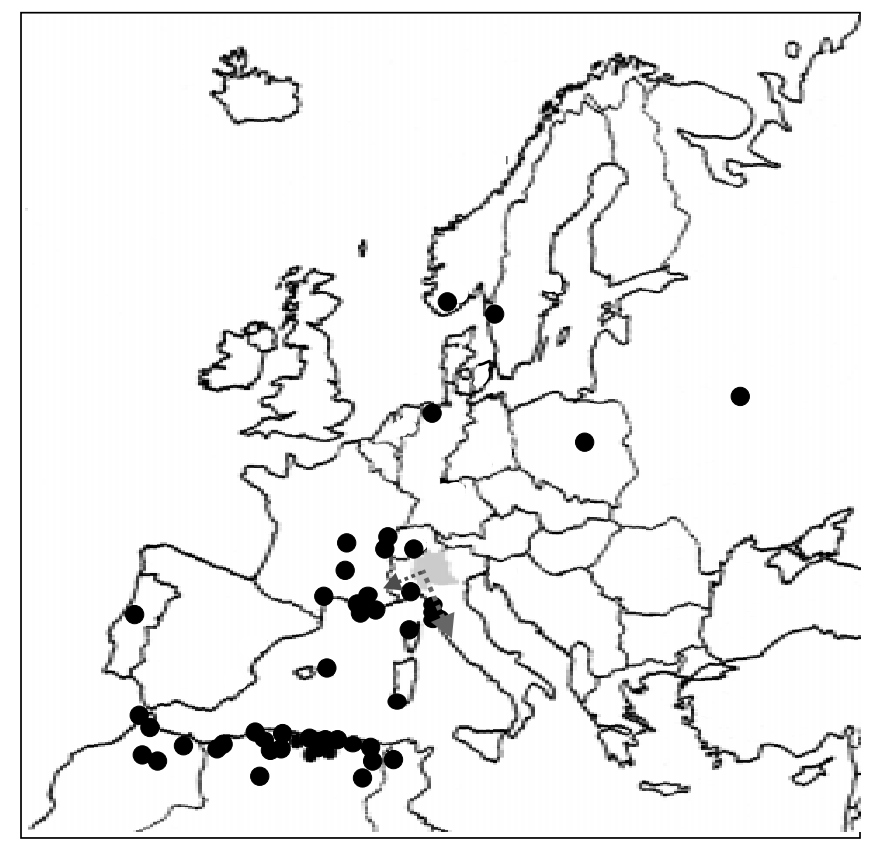

Fig. 3. Distribution of recoveries of Robins ringed in Lombardy region in 1975-2005 (after Vigorita and Reguzzoni 1994, 2004, modified). Grey area indicates the study site location, arrows reflect mean directions showed by tested birds. 
them was found six days after catching $\left(1062 \mathrm{~km}, 199^{\circ}\right)$. Twelve individuals were found in France (distance from 257 to $527 \mathrm{~km}$, average angle $-230^{\circ}$ ), four birds were noted in Morocco (distance - above $1300 \mathrm{~km}$, average angle - 213 ) and one individual in Portugal $\left(1564 \mathrm{~km}, 247^{\circ}\right)$, one in Tunisia $\left(1032 \mathrm{~km}, 184^{\circ}\right)$ and one in Spain (10 days after ringing, $\left.8572 \mathrm{~km}, 210^{\circ}\right)$. Some recoveries were obtained from Italy; five individuals noted in Tuscany region (distance from 221 to $299 \mathrm{~km}$, angles $-155^{\circ}$ and $\left.159^{\circ}\right)$.

The distribution of all recoveries for the Blackcap is given in Figure 4. For Blackcaps ringed at Arosio five ringing recoveries were obtained. Two of them were ringed during autumn migration and found in winter quarters - one individual in Spain, one in Algeria. For the whole Lombardy region the number of recoveries was 29, six of them were noted during autumn passage - in Algeria (four individuals; distance - above $1100 \mathrm{~km}$, average angle $-202^{\circ}$ ), Spain (one individual; $1162 \mathrm{~km}$, $225^{\circ}$ ) and France (one individual; $345 \mathrm{~km}, 218^{\circ}$ ).

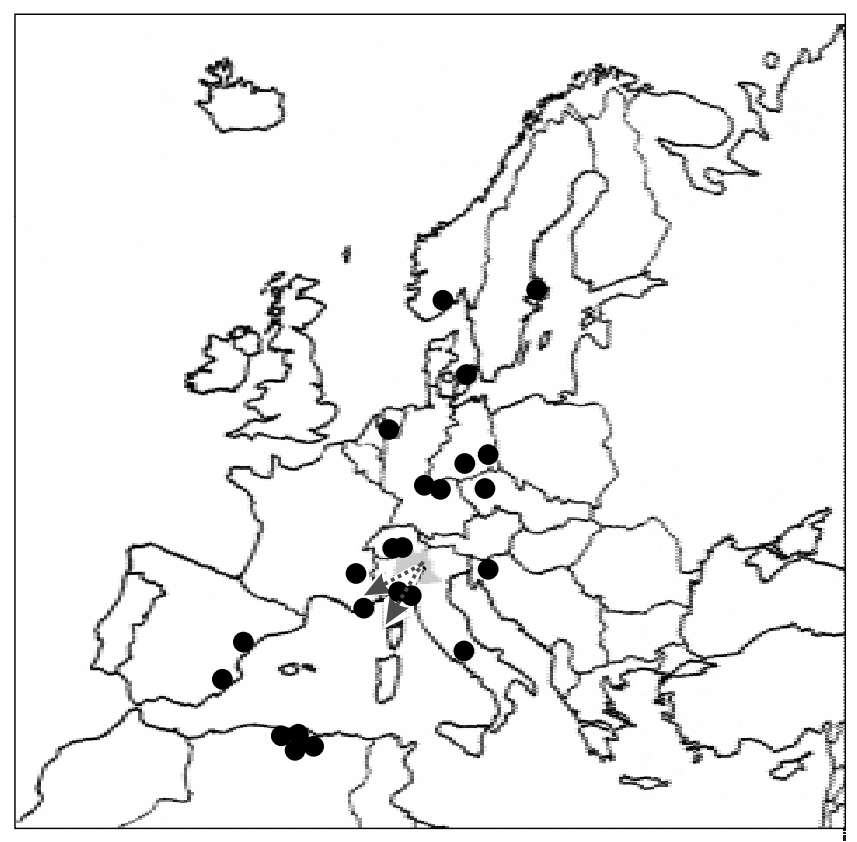

Fig. 4. Distribution of recoveries of Blackcaps ringed in Lombardy region in 1975-2005 (after Vigorita and Reguzzoni 2002, 2004, modified). Grey area indicates the study site location, arrows reflect mean directions showed by tested birds.

\section{DISCUSSION}

Most populations of the Robin are partially migratory, totally migratory in the north-east of range and probably largely sedentary in the south of Europe. Autumn migration lasts from September till the end of October; passage in the south ap- 
pears to occur slightly later than in the north (Cramp 1993). Main movement of the Blackcap through northern and central Europe takes place in September, diminishing through October, while highest numbers occur mid-September to October in Lombardy, northern Italy (Schubert et al. 1986). If the Busse's method is applied to a group of birds that is large enough and homogenous, then one can expect the observed pattern to be clear. Orientation tests were performed during 30 days, this period contained migration peaks of both tested species. The season was studied in great detail, samplings were collected regularly. The data are representative, especially in case of the Robin, with total number of 220 performed tests. They seem to be a promising material for further analyses. Cage tests are generally good method for studying orientation behaviour in the field. They allow to define directional behaviour of birds at different localities during real migration. This method was often used for studying directional preferences of nocturnal migrants such as Robins and Blackcaps. Nowakowski and Malecka (1999) focused on the analysis of Robins migrating across central part of Poland, Ściborska and Busse (2004) - along the Baltic coast, while Adamska and Filar (2005) - in southern Poland. Busse et al. (2001) in their study focused on the Blackcap and Robin tested at several stations in central and eastern part of Europe. However, there is lack of data of directional preferences of these species in northern Italy. So far, at considered station - Arosio Bird Observatory - only Song Thrushes (Turdus philomelos) were tested in orientation cages - Emlen funnels (Huttunen 2004).

Tested species have shown differentiation of directional preferences. Distribution of directions for the Robin is very clear. One direction was preferred - SSE direction (34\%). SW direction was not clearly marked on radar graph, picture was diffused, but these pattern and percentage of SW headings (23\%) could indicate migration in this direction. Average azimuth of SW direction specified with linear graphs was $148^{\circ}$. In the case of Blackcaps we can distinguish two main directions SSW direction as the dominant one (23\%), and also significant WSW direction $(22 \%)$. The SW direction (angle $-225^{\circ}$ ) was showed also by Blackcaps caught in southern Italy and tested in Emlen funnels (Spina et al. 1995).

It was quite often observed that directional preferences of birds tested during autumn migration pointed to the northern (reversed) directions, opposite to normal direction during autumn migration. This phenomenon could be explained according to the axial behaviour hypothesis, i.e. that birds have genetically encoded migration direction axiality - directed towards breeding and wintering grounds (Busse 1992). During specific conditions of orientation cage it is possible that a bird would like to leave the cage in the direction that is opposite to the standard one during its autumn migration. Stressed by the limited space of the cage birds could show directions towards familiar environment and places well-known for them, i.e. direction of their arrival. Such cases of the reversed migration were observed in natural conditions by Busse (1992) or Remisiewicz and Baumanis (1996). High percentage of northward directions during autumn migration was observed in Robins tested at the Polish Baltic coast in 1996 - 48.9\% (Busse and Trocińska 1999). Also in 
the southern part of Poland Robins tested in orientation cages showed more than $60 \%$ of reversed headings (Adamska and Filar 2005). On the contrary, at the Arosio station the percentage of reversed directions was lower and it constituted $37 \%$ for both tested species. This low number of reversed directions is probably connected with specific character of place, its topography and geographical position. Arosio station is situated on the top of a hill, surrounded by the Alps from the north. It is possible that birds tested in places that are located near some natural geographical barriers (such as sea, oceans or in the considered case - mountains), show less "nonsense" opposite headings than birds tested at other stations.

Both tested species have complicated strategies of migration through Europe. Birds migrating through northern Italy should be regarded as different migrating populations (Remisiewicz et al. 1997, Remisiewicz 2002, Mokwa 2004), in both cases it is also combination of resident and migratory populations (Schubert et al. 1986). However, migration pattern of the Robin was strongly determined in one SSE direction, which indicates the Apennine Peninsula. Main wintering area of this species lies from Ireland and Britain south to Morocco and south-east through Europe. Notable concentrations occur in Mediterranean basin, including areas where breeding does not take place, e.g. parts of Iberian and Yugoslavian coasts, southern Turkey, and most Mediterranean islands (Cramp 1993). Based on ringing recoveries (see Fig. 3) the tested birds were expected to orientate south-west. Surprisingly, Robins tested in orientation cages showed strong tendency towards SSE $\left(163^{\circ}\right)$. Some recoveries obtained in Italy during migration season confirmed this direction; two individuals were noted beyond this region in Italy - Tuscany region (distance -221 and $277 \mathrm{~km}$, angle $-159^{\circ}$ ), those birds moved to SE direction, which supports results of experiments. Moreover, three birds were noted in this region $\left(299 \mathrm{~km}, 155^{\circ}\right)$ in December (two individuals) and in January (one individual). Robins showing direction to the Apennine Peninsula could indicate southern Italy as winter quarters. The Po Valley region is an important wintering area for resident and migratory species (Vigorita et al. 1986). It is possible that migration in SSE direction was typical for birds that migrate at the end of the season and finish their passage. It could be also local migratory direction consistent with their migratory routes. It is worth noting that these results were also in accordance with proposed migratory routes of this species through European continent ("Alpine routes" - Remisiewicz et al. 1997, Remisiewicz 2002). In both cases we could observe small number or lack of obtained recoveries in southern Italy. Ringing in the southeastern areas was not so popular, but it does not mean that birds do not migrate in this direction. Most of recoveries were obtained in Algeria - probably the birds caught and ringed in Italy migrate through Corsican and Sardinian Island to northern Africa (Scebba and Olivieri del Castillo 1983). This migratory route is documented by migration of birds ringed in the Baltic region (Fig. 5). The SW direction, although not clearly marked on graphs was strongly supported by recovery data from France, Portugal, Morocco and Algeria ("Mediterranean route" - Remisiewicz 2002). Taken together, Robins caught in northern Italy could be the birds 
directed towards SW to western winter quarters and indicated SSE direction to winter quarters in southern Italy, Tunisia and also Algeria.

The Blackcap demonstrates wide variety of strategies, with populations from different parts of range varying from resident to migratory (Cramp 1993). The experiments showed two directions - SSW and WSW, which indicate western winter quarters. Main wintering areas of Blackcap lie in sub-Saharan Africa: western Africa, west of Greenwich meridian; southern Sudan, Ethiopia and Eritrea; equatorial eastern Africa south of Lake Nyasa (Cramp 1993). The results of orientation tests were in accordance with recovery data. The mean angles obtained from orientation

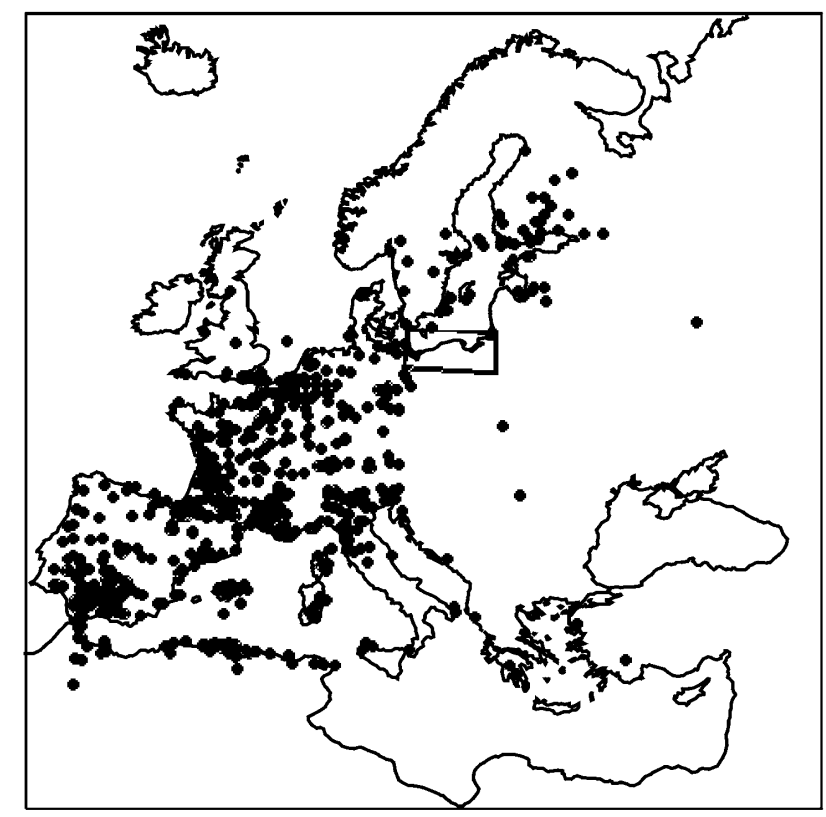

Fig. 5. Distribution of recoveries of Robins ringed in the Baltic region in 1961-1999 (after Busse 2000)

tests were $197^{\circ}$ and $240^{\circ}$. Both preferred directions - WSW and SSW were strongly supported by the recoveries. Birds found in Spain and France reflect migration towards WSW; records from Algeria support the SSW direction. Both of these directions were distinct, which may suggest that two different populations of the Blackcap migrate through northern Italy. These results were in accordance with migration strategies and migratory routes through European continent proposed for this species (Mokwa 2004). Author pointed out differentiation of Blackcaps that migrated during autumn passage in Italy - first group of birds directed to WSW to southern France and Spain, whereas the second one migrated through Corsican and Sardinian Islands. Both of them are short-distance migrants. Obta- ined results seem to be very interesting and promising but only intensive studies, especially in 
areas indicated by tested birds, could give information about migration pattern of these species.

\section{ACKNOWLEDGEMENTS}

We are very grateful to the organisers of the research and all the people from this station for help, especially to G. Bana, President of Fondazione Europea IL NIBBIO, who enabled us to collect all the data that we used in this study.

\section{REFERENCES}

Adamska K., Filar M. 2005. Directional preferences of the Chiffchaff (Phylloscopus collybita) and the Robin (Erithacus rubecula) on autumn migration in the Beskid Niski Mountains (S Poland). Ring 27, 2: 159-176.

Akesson S. 1993. Effect of geomagnetic field on orientation of the Marsh Warbler, Acrocephalus palustris, in Sweden and Kenya. Anim. Behav. 46: 1157-1167.

Berthold P., Helbig A.J., Mohr G., Querner U. 1992. Rapid microevolution of migratory behaviour in a wild bird species. Nature 360: 668-669.

Busse P. 1992. Migratory behaviour of Blackcaps (Sylvia atricapilla) wintering in Britain and Ireland: contradictory hypotheses. Ring 14, 1-2: 51-75.

Busse P. 1995. New technique of a field study of directional preferences of night passerine migrants. Ring 17, 1-2: $97-116$.

Busse P. 2000. Bird Station Manual. Gdańsk.

Busse P., Gavrilov V.M., Ivliev V., Nowakowski J.K. 2001. Differentiation of directional preferences of some nocturnal migrants on autumn migration across the central and Eastern Europe. Ring 23, 1-2: 119-130.

Busse P., Trocińska A. 1999. Evaluation of orientation experiment data using circular statistic doubts and pitfalls in assumptions. Ring 21, 2: 107-130.

Cramp S. (Ed.). 1993. The Birds of the Western Palearctic. Handbook of the Birds of Europe, the Middle East and the North Africa. vol. 7. Oxford. Univ. Press, Oxford - New York.

Emlen S.T., Emlen J.T.J. 1966. A technique for recording migratory orientation of captive birds. Auk 83: 361-367.

Gwinner E., Wiltschko W. 1978. Endogenously controlled changes in the migratory direction of the Garden Warbler, Sylvia borin. J. Comp. Physiol. 125: 267-273.

Helbig A. J. 1991. Inheritance of migratory direction in a bird species: a cross-breeding experiment with SEand SW-migrating blackcaps (Sylvia atricapilla). Behav. Ecol. Sociobiol. 28: 9-12.

Helbig A. J., Berthold P., Wiltschko W. 1989. Migratory Orientation of Blackcaps (Sylvia atricapilla): Population-specific Shifts of Direction during the Autumn. Ethology 82: 307-315.

Huttunen M.J. 2004. Orientation and migratory activity of Song Trushes (Turdus philomelos) in northern Italy: cage and release experiments under overcast conditions. Ring 26, 1: 23-39.

Kramer G. 1949. Uber richtungstendenzen bei der nähtlichem Zugunruhe gekäftiger Vögel. In: Ornithologie als Biologische Wissenschaft. Heidelberg.

Mokwa K. 2004. Migration strategies European populations of the Blackcap Sylvia atricapilla. Ph.D. thesis, University of Gdańsk.

Nowakowski J.K., Malecka A. 1999. Test of Busse's metod of studying directional preferences of migrating small Passeriformes. Acta orn. 34: 37-44.

Remisiewicz M. 2002. The spatio-temporal pattern to Robin Erithacus rubecula migration-evidence from ringing recoveries. In: Both C., Piersma T. (Eds). The avian calendar: exploring biological hurdles in the annual cycle. Proc. $3^{\text {rd }}$ Conf. European Orn. Union, Groningen, August 2001. Ardea 90, 3 (special issue): 489-502.

Remisiewicz M., Baumanis J. 1996. Autumn migration of Goldcrest (Regulus regulus) at the eastern and southern Baltic coast. Ring 18, 1-2: 3-36. 
Remisiewicz M., Nowakowski J. K., Busse P. 1997. Migration pattern of Robin (Erithacus rubecula) on the basis of Polish ringing recoveries. Ring 19, 1-2: 3-40.

Sauer E.G.F. 1957. Die Sternorientierung nähtlich zeihender Grasmuckën (Sylvia atricapilla, borin und curruca). Zeit. Tierpsychol. 14: 29-70.

Scebba S., Olivieri del Castillo M. 1983. Migrazione e svernamento del Pettirosso Erithacus rubecula in Italia: anansi delle riprese. Atti III Conv. Ital. Orn.: 105-106.

Scebba S., Capasso S. 2006. Monitoraggio della migrazione post-nuziale dell'Osservatorio Ornitologico di Arosio. Milano.

Schubert M., Fedrigo A., Massa R. 1986. Timing and pattern of the post-breeding migration of some species of passerines through Lombardy, Northern Italy. Ring. \& Migr. 7: 15-22.

Ściborska M., Busse P. 2004. Intra-seasonal changes in directional preferences of Robins (Erithacus rubecula) caught on autumn migration of Bukowo-Kopan ringing station (N Poland) in 1996. Ring 26, 1: 41-58.

Spina F., Berthold P., Helbig A., Querner U. 1995. Migratory activity and orientation an Italian Blackcap (Sylvia atricapilla) population. Suppl. Ric. Biol. Selvaggina XXII (1995): 475-482.

Trocińska A., Leivits A., Nitecki C, Shydlovsky I. 2001. Field studies of directional preferences of the Reed Warbler (Acrocephalus scirpaceus) and the Sedge Warbler (A. schoenobaenus) on autumn migration along the eastern and southern coast of the Baltic Sea and in western part of Ukraine. Ring 23, 1-2: 109-117.

Vigorita V., Fornasari L., Carabella M., Massa R. 1986. A winter terrestrial bird census in Lombardy. Supp. Ric. Biol. Selv. 10: 385.

Vigorita V., Reguzzoni P.A. 1994. Osservatori Ornitolologici: relazioni annuale sull'inanellamento per lo studio delle migrazioni degli uccelli nella Regione Lombardia, 1993. vol. XVII. Regione Lombardia, Milano.

Vigorita V., Reguzzoni P.A. 2002. Osservatori Ornitolologici: relazioni annuale sullinanellamento per lo studio delle migrazioni degli uccelli nella Regione Lombardia, 2001. vol. XXV. Regione Lombardia, Milano.

Vigorita V., Reguzzoni P.A. 2004. Osservatori Ornitolologici: relazioni annuale sull'inanellamento per lo studio delle migrazioni degli uccelli nella Regione Lombardia, 2003. vol. XXVII. Regione Lombardia, Milano. 